\title{
USO DE SUBSTÂNCIAS FARMACOLÓGICAS ATRAVÉS DA MESOTERAPIA NO TRATAMENTO DA GORDURA LOCALIZADA
}

\author{
Lhorena Paula da Silva Lourenço ${ }^{1}$ \\ Elaine Miranda Padilha Duarte ${ }^{2}$ \\ Barbara Xavier Barbosa Martins ${ }^{3}$ \\ Débora Cristina Rodrigues Sousa ${ }^{4}$ \\ Doris Cristina Freitas Dolabela ${ }^{5}$ \\ Shenia Miranda Ribeiro 6 \\ Rayka Alves Fernandes? \\ Luiz Fernando Alves dos Reis ${ }^{8}$
}

RESUMO: A procura no mercado por procedimentos estéticos tem apresentado progressivo crescimento, uma vez que oferece ao consumidor uma diversidade de recursos terapêuticos visando a harmonização corporal e a satisfação pessoal. Recursos como a mesoterapia que facilita o processo de lipólise têm sido cada vez mais procurados, visto que o aumento da gordura corporal principalmente a localizada, contribui para a baixa autoestima, interferindo diretamente na qualidade de vida. Este trabalho tem como objetivo realizar uma revisão de literatura sobre a eficácia da utilização da mesoterapia no tratamento de gordura localizada. Para alcançar os objetivos propostos, utilizou-se como recurso metodológico, a pesquisa bibliográfica exploratória com caráter descritivo, tendo como bases documentos extraídos de dados virtuais Scientific Electronic Library Online (Sciello), Google acadêmico e demais sites científicos, para obtenção de artigos, teses, monografias, dissertações e livros envolvidos no tema proposto. As palavras-chave utilizadas para a pesquisa foram: mesoterapia, gordura localizada, tecido adiposo, hipoderme, ação lipolítica, metabolismo dos adipócitos. A mesoterapia com uso de substâncias lipolíticas, aminoácidos, vitaminas, promove a quebra de triglicerídeos e a liberação de ácidos graxos livres no tecido adiposo, havendo diminuição significativa da biometria corporal de forma rápida e segura. Cabe ao biomédico qualificado, determinar a terapêutica indicada e as substâncias a serem utilizadas mediante a avaliação individual de cada paciente.

Palavras-chave: Mesoterapia. gordura localizada. tecido adiposo.

ABSTRACT: The market demand for aesthetic procedures has shown a progressive growth, since it offers the consumer a variety of therapeutic resources aimed at body harmonization and personal satisfaction. Resources such as mesotherapy that facilitates the lipolysis process have been increasingly sought after, since the increase in body fat, especially

\footnotetext{
${ }^{1}$ Graduanda de Biomedicina/ Faculdade única. E-mail:1horenapaular999@gmail.com

${ }^{2}$ Graduanda de Biomedicina na Faculdade Única Ipatinga. E-mail:elainemirandapduarte@gmail.com

3 Graduanda de Biomedicina faculdade única. E-mail:esteticabarbaraxavier@gmail.com

${ }^{4}$ Graduanda na faculdade única de Ipatinga.E-mail:debora_sousazoos@hotmail.com

${ }^{5}$ Graduanda de Biomedicina / Faculdade Única. E-mail:dorisfreitas2@gmail.com

${ }^{6}$ Graduaçãoem biomédica Única Ipatinga. E-mail: sheniamiranda@hotmail.com

7 Graduanda de Biomedicina na Faculdade Única Ipatinga. E-mail:raykafernandes@gmail.com

${ }^{8}$ Professor do curso de Biomedicina da Faculdade Única de Ipatinga.
} 
localized, contributes to low self-esteem, directly interfering in the quality of life. This work aims to conduct a literature review on the effectiveness of using mesotherapy in the treatment of localized fat. To achieve the proposed objectives, exploratory bibliographic research with a descriptive character was used as a methodological resource, based on documents extracted from virtual data Scientific Electronic Library Online (Sciello), Google academic and other scientific sites, to obtain articles, theses, monographs, dissertations and books involved in the proposed theme. The keywords used for the research were: mesotherapy, localized fat, adipose tissue, hypodermis, lipolytic action, adipocyte metabolism. Mesotherapy using lipolytic substances, amino acids, vitamins, promotes the breakdown of triglycerides and the release of free fatty acids in adipose tissue, with a significant decrease in body biometrics quickly and safely. It is up to the qualified biomedical doctor to determine the indicated therapy and the substances to be used through the individual assessment of each patient.

Keywords: Mesotherapy localized Fat.adipose tissue.

\section{INTRODUÇÃO}

A busca incessante pelo "belo" marca o padrão de beleza estabelecido pela sociedade no século XXI. A preocupação com o corpo escultural, belo e livre de imperfeições, torna a população um tanto quanto "escrava" desse estereótipo de beleza exposto pela mídia. E a necessidade que as pessoas sentem em estar dentro de um padrão de beleza cultural, social e individual acarreta em baixa autoestima, ansiedade e distorção da imagem corporal. A supervalorização do corpo do público feminino e masculino vem se igualando na mesma na proporção e a gordura localizada tem sido um dos principais fatores responsáveis pela crescente busca de tratamentos estéticos, apesar de se conhecer a problemática de saúde que envolve a gordura localizada (DE ALMEIDA, N.S.; DA SILVA, L., 2017; DAMASCENO, D. G. S., 2018; SEVERO, V. F.;

VIEIRA, E., 2018; RINALDI, P. O. O. B., 2019). A mesoterapia vem sendo amplamente utilizada por ser um procedimento menos invasivo e não cirúrgico que auxilia no recontorno corporal. Sendo assim, resultados mais eficazes são observados em indivíduos que estão próximos ao seu peso desejável e buscam apenas a remoção de pequenas áreas especificas de gordura corporal, visto que não é um tratamento indicado para a obesidade. Os pacientes geralmente apresentam resultados imediatos com perda de dois tamanhos no manequim e melhora na qualidade da pele, gerando maior satisfação, além de ser um procedimento suportável e não necessitar de período de recuperação (ALVES, M., 2017).

$\mathrm{O}$ aumento da gordura corporal principalmente a localizada, contribui para a baixa autoestima, interferindo diretamente na qualidade de vida. Em vista disso, a busca pela saúde do corpo e boa forma física recebe grande destaque nos tempos atuais em nossa sociedade, favorecendo a crescente busca por serviços e tratamentos estéticos na tentativa de melhorar a aparência corporal com o objetivo de proporcionar benefícios inigualáveis, incluindo uma melhora dos aspectos perceptivo, cognitivo, emocional e comportamental. Portanto, para estabelecer intervenções estratégicas adequadas é necessário o conhecimento teórico e prático sobre a disfunção estética em questão, suas causas, manifestações fisiológicas e saber intervir nos mecanismos envolvidos, a fim de obter sucesso nos resultados dos protocolos estéticos. 
O objetivo geral deste trabalho é realizar uma revisão de literatura sobre a eficácia da utilização da mesoterapia no tratamento de gordura localizada, além de citar as propriedades e estrutura do tecido adiposo, bem como o metabolismo dos adipócitos, descrever os aspectos da gordura localizada, apresentar a mesoterapia e substâncias farmacológicas e suas respectivas funções como opção de tratamento para a gordura localizada.

\section{MATERIAL E MÉTODOS}

Para alcançar os objetivos propostos, utilizou-se como recurso metodológico, a pesquisa bibliográfica exploratória com caráter descritivo, tendo como bases documentos extraídos de dados virtuais Scientific Electronic Library Online (Sciello), Google acadêmico e demais sites científicos, para obtenção de artigos, teses, monografias, dissertações e livros envolvidos no tema proposto.

As palavras-chave utilizadas para a pesquisa foram: mesoterapia, gordura localizada, tecido adiposo, hipoderme, ação lipolítica, metabolismo dos adipócitos. Posteriormente, ocorreu a leitura interpretativa e seleção das publicações, cujo critério de inclusão englobou assuntos relacionados ao tema e artigos publicados nos últimos onze anos, ressalvando as principais ideias para compor o estudo.

\section{DESENVOLVIMENTO}

\section{Tecido adiposo}

O tecido adiposo é um tecido conjuntivo frouxo localizado embaixo da pele, especificamente na hipoderme, considerado o principal reservatório de energia do organismo. Além disso, funciona como uma barreira física ao trauma, sustentando e protegendo os órgãos, atua como isolante térmico e secreta inúmeros peptídeos e proteínas bioativas, denominadas adipocinas que possuem ação local e à distância (LOFEU, G.; DE BRITO, L.; BARTOLOMEI, K., 20I5; LACERDA, M.; MALHEIROS, G.; DE ABREU, A., 2016).

A arquitetura do tecido adiposo mostra que as células adiposas estão no íntimo dos septos de tecido conjuntivo, cuja função é conectar a derme reticular à fáscia muscular. Essa arquitetura tecidual pode se diferenciar em ambos os sexos. Nas mulheres estes septos apresentam conformação vertical, são mais frouxos e alojam células de gordura maiores, enquanto nos homens estão dispostos na diagonal rígida, alojando pequenos adipócitos (SEVERO, V.; VIEIRA, E., 2018).

O adipócito é o principal componente celular do tecido adiposo, derivado dos fibroblastos, o qual possui a função de acumular o excedente de calorias em forma de triacilglicerol (TAG) no interior do seu citoplasma (DA SILVA, B.; ROSA, T., 2015). Os TAG são lipídeos armazenados pelo corpo em grandes quantidades (OLIVEIRA, E., 2015).

\section{Metabolismo dos adipócitos}

O metabolismo do tecido adiposo é dividido em fases distintas de acordo com as ações metabólicas sendo elas, lipogênica e lipolítica. A primeira refere-se a todos os processos metabólicos resultantes da biossíntese, incorporação e armazenamento de TAG no interior 
da gordura intracitoplasmática. Já a lipólise é um processo no qual ocorre catabolismo da gordura estocada. Esse evento é controlado por hormônios (catecolaminas, glucagon,

tirotropina, paratormônio, hormônio melanócito estimulante e adrenocorticotropina), assim como citocinas e adipocinas. Além disso, os sistemas nervoso simpático e parassimpático também contribuem para o metabolismo do tecido adiposo (ZECHNER, R. et al., 2009; DAMACENO, D., 2018).

Os adipócitos possuem receptores $\beta$-adrenérgicos (agonistas) como mostra a Figura I, encarregados pela lipólise e $\alpha_{2}$ - adrenérgicos (antagonistas) associados à proteína $G$ estimuladora e inibidora responsáveis pela lipogênese, respectivamente. Quando o receptor ßadrenérgico é estimulado por meio das catecolaminas, ocorre a ativação da enzima de membrana adenilciclase, a qual é incumbida de converter a adenosina trifosfato (ATP) em adenosina monofosfato cíclica (AMPc). Durante o processo lipolítico as concentrações de AMPc intracelular aumentam e posteriormente desencadeia a ativação da proteína quinase inativa, que por sua vez irá fosforilar no adipócito a enzima lipase, sendo esta responsável por hidrolisar os TAGs (DE FREITAS, E. et al., 2012; KRUPEK, T. et al., 2012; DA SILVA PINHO, S.; DE SOUZA, F., 2017).

O resultado final da lipólise consiste na liberação de moléculas de ácidos graxos (AG) e glicerol que são transportados do citosol das membranas celulares para a circulação sanguínea. $\mathrm{O} A \mathrm{AG}$ atravessa a membrana da célula do adipócito, se liga a albumina sérica e é conduzido pela corrente circulatória até as células que o utilizam; e o glicerol que é hidrossolúvel no plasma é captado e oxidado no fígado (DE ALMEIDA SALOMÃO, A., 2012; DE FREITAS, E. et al., 2012; DAMACENO, D., 2018).

FIGURA I - Mecanismo de ação da lipólise.

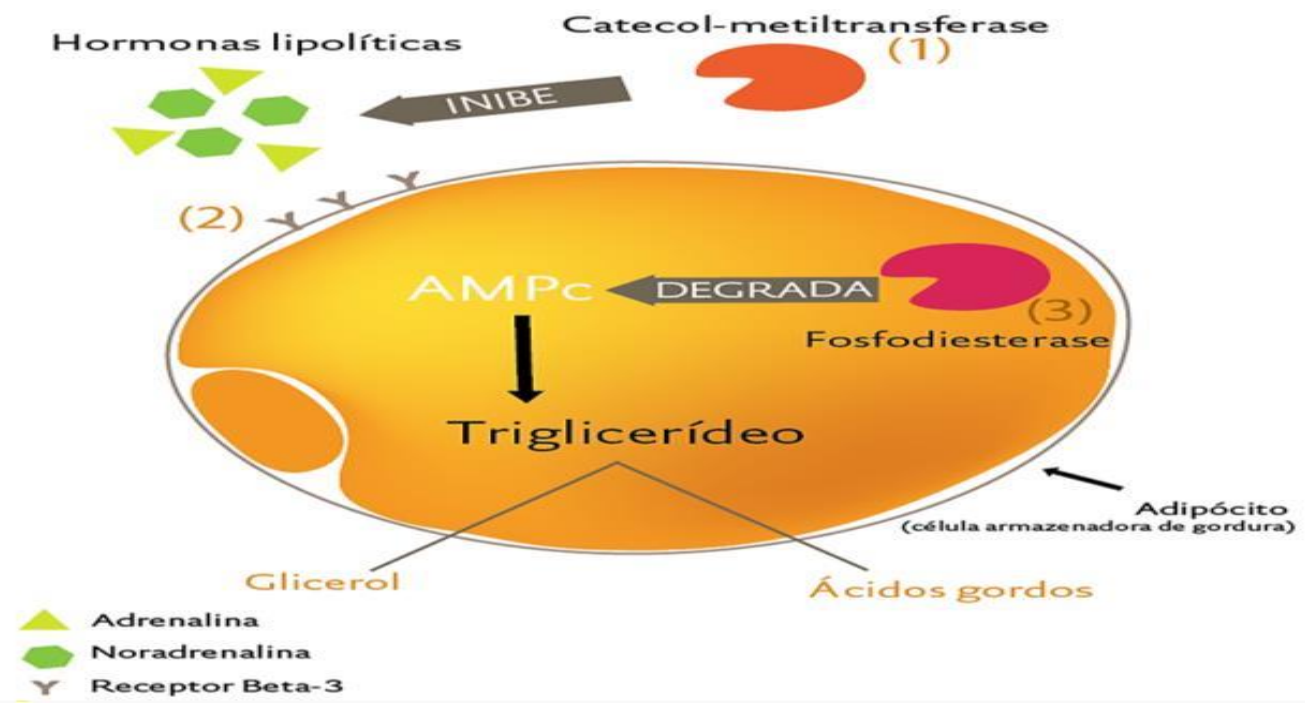

Fonte: SEVERO, V.; VIEIRA, E., (2018).

\section{Gordura localizada}


A gordura localizada ou lipodistrofia localizada é uma alteração que ocorre nas células adiposas resultante de um distúrbio no metabolismo de gordura, fazendo com que o tecido conjuntivo subcutâneo apresente irregularidades e aparência ondulada em regiões especifica

como os quadris, flancos, oblíquo, abdômen e coxas (BRAGA, L.; LOUSADA, M., 2018; SEVERO, V.; VIEIRA, E., 2018).

O desenvolvimento do processo de gordura corporal está relacionado à hiperplasia celular, aumento no número de células adiposas; e a hipertrofia celular, aumento no volume das células já existentes, bem como a combinação destes dois fenômenos. Os fatores que predispõem ao acúmulo de gordura podem ser de origem genética ou ocasionada por alterações posturais ou circulatórias. Entre os fatores externos que podem agravar os predisponentes, estão o estresse, maus hábitos alimentares, tabagismo, sedentarismo e disfunções no organismo em geral (LOFEU, G.; DE BRITO, L.; BARTOLOMEI, K., 20I5; MEYER, G.; RODRIGUES, L., 2017).

A lipodistrofia localizada do abdômen é chamada de gordura superior ou gordura androide, acometendo com maior frequência nos homens. A gordura nesta região está associada a uma maior morbimortalidade quando comparada a aquela gordura distribuída abaixo da cintura, denominada de gordura ginoide ou periférica, principalmente localizada na região da pelve e coxa superior, ocorrendo mais frequente em mulheres (BRAGA, L.; LOUSADA, M., 2018).

\section{Mesoterapia}

A mesoterapia também denominada como intradermoterapia, é uma técnica minimamente invasiva e não cirúrgica introduzida na França pelo médico Michel Pistor no ano de 1952. Ela consiste na aplicação de fármacos altamente diluídos ou substâncias bioativas por via subcutânea ou intradérmica, em múltiplos pontos, garantindo assim a chegada da substância em alta concentração no local a ser tratado (ALVES, M., 2017; DA SILVA ALVES, H., 2017; CASTAÑEDA, S., 2020).

A técnica clássica de aplicação é conhecida popularmente como aplicação ponto-a-ponto. A introdução da agulha na pele varia de autor para autor, descreve-se que pode ser perpendicularmente a pele ou formando um ângulo de $30^{\circ}$ a $60^{\circ}$. É preconizada a utilização da agulha de Lebel (bisel com $4 \mathrm{~mm}$ de comprimento). Sugere-se a aplicação de pequenos volumes do fármaco por puntura, sendo de 0,02 a o,05 $\mathrm{mL}$, entre uma distância de I $\mathrm{cm}$ e no máximo $4 \mathrm{~cm}$ entre eles, abrangendo somente a área a ser tratada. As aplicações são realizadas com periodicidade semanal ou mensal e as quantidades de sessões variam entre quatro e dez de acordo com a necessidade de cada paciente (HERREROS, F.; MORAES, A.; VELHO, P., 2011; DE SOUSA, P., 2012).

Em tese, a principal vantagem desse método é uma resposta terapêutica rápida e mais eficaz quanto ao estímulo, pois ela é capaz de estimular o tecido tanto através da puntura quanto pela ação dos fármacos sem fazer uso de medicação sistêmica. A derme por apresentar farmacocinética própria, torna-se um reservatório a partir de quais os produtos ativariam receptores dérmicos e se difundiriam lentamente, promovendo uma maior permeabilidade celular e vasodilatação, levando mais tempo para atingir a microcirculação sanguínea e, por conseguinte, favorecendo a chegada das substâncias no local de ação (MAMMUCARI, M. et al., 2oIr; MOURA FILHO, F., 2017; SEVERO, V.) 


\section{Fármacos}

Para atender as particularidades de cada paciente, recomenda-se que a formulação seja manipulada, levando em consideração o mecanismo de ação de cada princípio ativo. Eles podem ser classificadas em lipolíticos, ativando a lipólise em células de gorduras através da inibição da fosfodiesterase, enzima responsável pela degradação do mediador químico intracelular AMPc em AMP; além de induzir e regular a proliferação dos fibroblastos e a drenagem dos tecidos; termogênicos, estimulando a energia local, através do aumento do metabolismo celular, facilitando a queima de gordura e a drenagem mais rápida dos edemas; e vasodilatadores, que atuam no interstício, acelerando e regulando o metabolismo celular, melhorando a circulação e auxiliando na absorção de outros ativos (SEVERO, V., VIEIRA, E., 2018).

Entre os ativos mais utilizados estão a fosfatidilcolina, também chamada de lectina, é considerada um detergente, por apresentar uma ação emulsificante atua diminuindo a tensão superficial das células, gerando partículas menores de gordura em forma de triglicerídeos, o que ocasiona diversas alterações no formato dos adipócitos, consequentemente resulta na perda de medidas nos locais onde foi aplicada

(GUYTON, A. C.; HALL, J. E., 2017; DAMASCENO,

D. G. S., 2018).

Uma das hipóteses estudadas para explicar o mecanismo de ação da fosfatidilcolina é que esse fármaco penetra nos adipócitos devido ao seu caráter anfipático. No citoplasma dessa célula a hidrólise da fosfatidilcolina acontece por meio da fosfolipase $\mathrm{D}$ que fornece o ácido fosfatídico, levando a ativação da proteína quinase $\mathrm{C}$ (PKC). A PKC ativada incentiva a transferência da lipase no citoplasma do adipócito para o vacúolo, onde os triglicerídeos são hidrolisados resultando em ácidos graxos e glicerol, sendo estes posteriormente metabolizados em outras vias ou eliminados na urina. Outra hipótese a ser considerada é a destruição dos adipócitos, sendo esta desencadeada pela ativação da via de inflamação ou por uma ação irritante da fosfatidilcolina diretamente sobre os adipócitos (DAMASCENO, D. G. S., 2018; LEMES, M. X., 2018).

A L-carnitina é um aminoácido geralmente associado aos ativos lipolíticos por atuar como coadjuvante, devido ao aumento da lipólise pode ocorrer o aumento de ácido graxo no interior dos adipócitos, tendendo a inibir a mesma. Ela influencia indiretamente no metabolismo glicídico e proteico, aumentando a transferência dos ácidos graxos para dentro da mitocôndria, permitindo assim que eles sejam oxidados pela adenosina trifosfato. Por sua vez, essa oxidação diminui o uso da glicose periférica, uma vez que possibilita a entrada de acetilas no ciclo de Krebs e consequentemente, aumenta a disponibilidade energética da célula promovendo a utilização dos mesmos, evitando assim desvios metabólicos (RIBEIRO, C., 2010; KRUPEK, T. et al., 2012; SEVERO, V., VIEIRA, E., 2018).

O silício orgânico é um elemento presente na estrutura do tecido conjuntivo, responsável por regular o metabolismo e a divisão celular. No tecido adiposo, ele estimula a síntese de AMPc e consequentemente, promove a hidrólise dos triglicerídeos (MENDES CABRAL, N., 2012).

A cafeína intervém no processo de lipólise através da inibição do mecanismo de ação da fosfodiesterase, com consequente amplificação do tempo de meia vida e aumento das concentrações de AMPc intracelular. O AMPc age como um segundo mensageiro celular, estimulando a enzima lipase a obter a quebra dos triglicerídeos armazenados nos adipócitos. A cafeína ainda possui um efeito estimulante que age na microcirculação do tecido cutâneo 
provendo o aumento da drenagem linfática no tecido adiposo, retirando o acúmulo de gordura e eliminando toxinas provenientes do processo de lipólise (ANNUNCIATO, R.; et al., 2009; GUERREIRO, M. M. V. C., 2012; OLIVEIRA, M. C. S., 20I8).

\section{CONCLUSÃO}

Compreende-se que o desequilíbrio entre o consumo excessivo de alimentos com elevado teor calórico em detrimento da demanda energética contribui para o depósito de gorduras em determinados locais do corpo, originando as chamadas gorduras localizadas. Sendo também estas condicionadas por fatores metabólicos, hormonais, genéticos, emocionais e de gênero.

O tratamento com a técnica de mesoterapia no tratamento de gordura localizada consiste em múltiplas punções no tecido subcutâneo de uma mescla de substâncias como lipolíticos, aminoácidos, entre outros, a fim de facilitar o processo de lipólise, ou seja, que promovem a quebra de triglicerídeos e liberação de ácidos graxos livres no tecido adiposo, havendo diminuição significativa da biometria corporal de forma rápida e segura. Cabe ao biomédico qualificado, determinar a terapêutica indicada e as substâncias a serem utilizadas de acordo com a necessidade de cada paciente, pois a escolha desse método é contraindicada para pacientes que apresentam problemas cardíacos, diabetes descompensada, doença renal, alergia aos componentes da mescla, pacientes com câncer, mulheres grávidas e lactantes. Quando bem empregado o resultado é positivo e reflete na área emocional,social e comportamental do indivíduo.

\section{REFERÊNCIAS}

[1] ALVES, M. M. Mesoterapia e risco cardiovascular: uma revisão narrativa da literatura. Trabalho de Conclusão de Curso (Bacharelado em Biomedicina) Universidade Federal Fluminense, Nova Friburgo, 2017.

[2] ANNUNCIATO, R. et al. Suplementação aguda de cafeína relacionada ao aumento de força. RBNERevista Brasileira de Nutrição Esportiva, v. 3, n. 18, 2009.

[3] BRAGA, L. L. B.; LOUSADA, M. L. R.

Criolipólise e o Tratamento da Lipodistrofia Localizada. Revista Estética em Movimento, v. I, n. I, 2018.

[4] CASTAÑEDA, S. Z. Conocimiento de la mesoterapia con ozono como mètedo de reducciòn de tallas a nivel corporal por parte del mèdico estètico y rol asistencial del esteticista para su aplicaciòn en clìnicas estèticas mèdicas de la ciudad capital en el perído comprendido de agosto-diciembre 2018. Tese de doutorado (Licenciatura en Administraciòn de Empresas Cosmèticas y Servicios Estèticos) - Facultad de Ciencias de la Salud, Universidad Galileo, Guatemala, 2020.

[5] DAMACENO, D. G. de S. Mesoterapia como tratamento para gordura localizada: uma revisão da literatura. Trabalho de Conclusão de Curso (Bacharelado em Biomedicina) - Centro

Universitário de Brasília, Brasília, 2018. 
[6] DA Silva Alves, H. H. et al. ATUAÇÃO DO FARMACÊUTICO NA SAÚDE

ESTÉTICA. Mostra Científica da Farmácia, v. 3, n. I, 2017.

[7] DA SILVA, B.; ROSA, T. Criolipólise e sua eficácia no tratamento da gordura localizada: revisão bibliográfica. Revista Visão Universitária, v. 3, n. I, 2015.

[8] DA SILVA PINHO, S.; DE SOUZA, F. G. L. Os efeitos da eletropolíse no tratamento da gordura localizada. 2017.

[9] DE ALMEIDA, N.S; DA SILVA, L. Efeitos do tratamento não invasivo na redução da gordura abdominal localizada sobre a composição corporal, variáveis cardiovasculares e autonômicas de mulheres eutróficas. Presidente Prudente, 2017.

[10] DE ALMEIDA SALOMÃO, A. Tratamento de gordura localizada e lipodistrofia ginóide com terapia combinada: radiofrequência multipolar, LED vermelho, endermologia pneumática e ultrassom cavitacional. Surgical \& Cosmetic Dermatology, v. 4, n. 3, p. 241-246, 2012.

[11] DE FREITAS, E. C. et al. Metabolismo lipídico durante o exercício físico: mobilização do ácido graxo. Pensar a Prática, v. 15, n. 3, 2012.

[12] DE SOUSA, P. M. A atuação do biomédico em procedimentos estéticos não invasivos e invasivos nãocirúrgicos. Trabalho de conclusão de curso - Graduação em Biomedicina, Universidade Católica de Brasília, Pró-Reitoria de Graduação, Distrito Federal, Brasília, 2012.

[13] GUERREIRO, M. M. V. C. Celulite 600 Processo/Produtos/Mercado. Dissertação de Mestrado (Ciências Farmacêuticas) Instituto Superior de Ciências da Saúde Egas Moniz, Portugal, 2016.

[14]

[15] GUYTON, A.C., HALL, J.E. Tratado de Fisiologia Médica. $3^{\text {a }}$ ed. Rio de Janeiro: Guanabara Koogan; 2017.

[16] HERREROS, F. O. C.; MORAES, A. M. de; VELHO, P. E. N. F. Mesoterapia: uma revisão bibliográfica. Anais Brasileiros de Dermatologia, v. 86, n. I, p. 96-ıoI, 2011.

[17] KRUPEK, T. et al. Mecanismo de Ação de Compostos Utilizados na Cosmética para o Tratamento da Gordura Localizada e da

Celulite. Saúde e Pesquisa, v. 5, n. 3, 2012.

[18] LACERDA, M. S.; MALHEIROS, G. C.; DE ABREU, A. de O. W. Tecido adiposo, uma nova visão: as adipocinas e seu papel endócrino. Revista Científica da FMC. Vol, v. II, n. 2, 2016.

[19] LEMES, B. X. Mesoterapia: Técnicas, substâncias lipolíticas e segurança clínica. Monografia (Farmácia Estética) - Faculdade Cathedral, Instituto Brasil de Pósgraduação, Belo Horizonte, 2018.

[20] LOFEU, G. M.; DE BRITO, L. R. A.; 
BARTOLOMEI, K. Atuação da radiofrequência na gordura localizada no abdômen: revisão de literatura. Revista da Universidade Vale do Rio Verde, v. 13, n. I, p. 571588, 2015 .

[21] MAMMUCARI, M. et al. Mesotherapy, definition, rationale and clinical role: a consensus report from the Italian Society of Mesotherapy. Eur Rev Med Pharmacol Sci, v. 15, n. 6, p. 682-694, 2011.

[22] MENDES CABRAL, N. E. Mestrado Integrado em Ciências Farmacêuticas. Dissertação de Mestrado (Ciências Farmacêuticas) - Instituto Superior de Ciências da Saúde Egas Moniz, Almada, 2012.

[23] MEYER, G.; RODRIGUES, L. Efeitos da vacuoterapia combinada à massagem modeladora no tratamento de lipodistrofia localizada abdominal. Tecnologia em Cosmetologia e Estética-Pedra Branca, 2017.

[24] MOURA FILHO, F. R. et al. Edema frontal após aplicação de minoxidil 5\% e biotina em injeções intradérmicas. Surgical \& Cosmetic Dermatology, v. 9, n. I, p. 94-95, 2017.

[25] OLIVEIRA, E. Triglicerídeos. Revista de Ciência Elementar, v. 3, n. 2, 2015.

[26] OLIVEIRA, M. C. S. Desenvolvimento e avaliação da estabilidade preliminar de uma emulsão cremosa contendo cafeína para o tratamento da lipodistrofia ginóide por massagem. Trabalho de Conclusão de Curso (Bacharelado em Farmácia) Universidade de Brasília, Faculdade de Ceilândia, Brasília, 2018.

[27] RIBEIRO, C. Cosmetologia aplicada à dermoestética. 2. Ed. São Paulo, Pharmabooks, 2010.

[28] RINALDI, P. O. O. B. Uso de formulações injetáveis no tratamento da gordura localizada. Revista Next Scientific, 2019.

[29] SEVERO, V. F.; VIERA, E. K. Intradermoterapia no tratamento de Gordura Localizada. Revista Saúde Integrada, v. II, n. 21, p. 27-39, 2018.

[30] ZECHNER, R. et al. Adipose triglyceride lipase and the lipolytic catabolism of cellular fat stores. Journal of lipid research, v. 50, n. I, p. 321, 2009. 